\title{
Body Fats Accumulate Metabolic Products: Physical and Chemical Analysis in Vitro
}

\author{
Kuat Pernekulovich Oshakbayev ${ }^{1, *}$, Kenneth Alibek, Igor Olegovich Ponomarev, Nurlybek Nurlanovich \\ Uderbayev $^{1}$, Bibazhar Abayevna Dukenbayeva ${ }^{2}$, Meruyert Gazaliyeva ${ }^{3}$, Pernekul Oshakbayev², Sholpan Kaliyeva ${ }^{3}$ \\ ${ }^{1}$ Republican Scientific Center for Emergency Medicine, Astana, the Republic of Kazakhstan \\ ${ }^{2}$ Astana Medical University, Astana, the Republic of Kazakhstan \\ ${ }^{3}$ Karaganda State Medical University, Karaganda, the Republic of Kazakhstan \\ *Corresponding author: okp.kuat@mail.ru
}

Received November 01, 2013; Revised January 10, 2014; Accepted February 12, 2014

\begin{abstract}
Objective: Aim of our study is to investigate physical and chemical structure and properties of body lipids at various anatomical sites. Trial design: A pilot physical and chemical descriptive experimental trial in vitro. Methods and Participants: Adipose tissue in the amount of 252 samples from 36 individuals (17 dead females) at autopsy. The subjects had died from various injuries and were between 36-60 years old. Interventions: Chemical groups and compounds were studied on infrared spectrometry with software, and atomic adsorptive analysis on spectrometer. Elemental chemical analysis of lipids different localization carried out. Research Subject: Chemical elements and compounds. Results: The highest levels of saturated fatty acids and almost all chemical groups and compounds analysed are found in dense atherosclerotic plaque (AP). In those samples, relatively more compounds containing metabolic products were identified $(\mathrm{P}<0.05, \mathrm{n}=252)$. Dense AP contains relatively more saturated and branched hydrocarbon chains, and they have the largest quantities of organic and inorganic elements and compounds in their structure. Conclusions: Human body lipids, especially dense AP, serve as a depot for various organic substances. Once having been formed, the AP has its own pathophysiological role in adsorption of redundant waste products.
\end{abstract}

Keywords: body lipids, atherosclerotic plaque, physical and chemical structure, composition

Cite This Article: Kuat Pernekulovich Oshakbayev, Kenneth Alibek, Igor Olegovich Ponomarev, Nurlybek Nurlanovich Uderbayev, Bibazhar Abayevna Dukenbayeva, Meruyert Gazaliyeva, Pernekul Oshakbayev, and Sholpan Kaliyeva, "Body Fats Accumulate Metabolic Products: Physical and Chemical Analysis in Vitro." American Journal of Medical and Biological Research, vol. 2, no. 1 (2014): 5-11. doi: 10.12691/ajmbr-2-1-2.

\section{Introduction}

The atherosclerotic plaque (AP) is one type of naturally occurring lipid-containing structures, which is a basic pathological element found in atherosclerosis (AS) [1]. According to morphological studies, AP is an inhomogeneous structural formation [2,3]. It is known from the literature that body lipids are heterogeneous and diverse both according to location and function [4]. For example, AP has a layered or multifocal form, often with significant predominance of one or another component, usually of atheromatous masses, fibrous structures, and calcifications [5].

There is not enough data in literature on the chemical structure and composition of lipids at various body locations [6]. What does the body fat else? The aim of our study was to investigate physical and chemical structures and properties of body lipids at various anatomical sites.

\section{Study Design}

A pilot physical and chemical descriptive experimental trial in vitro.

\subsection{Participants}

Adipose tissue in the amount of 252 samples was obtained from 36 individuals (19 males, 17 females) at autopsy. The subjects had died from various injuries and were between 36-60 years old. The autopsy material (lipids) was taken for research purposes after forensic medical examinations had been carried out. The criteria used for inclusion of material in this research were:

1. sampling was performed within 2 hours after death (interval of time between death and collection);

2. tissue donors had no chronic somatic diseases (such as cardiovascular, endocrine, cancer, etc) and cause of death was road accident.

Removal of autopsy material was performed at the Centre for Forensic Medical Examination of the city of Almaty. Tissue was collected from 7 various locations: visceral fat (VF), from the omentum and paranephric regions; subcutaneous fat (SF) from the buttocks, the abdomen (umbilical region), and shoulder; AP from the descending aorta; homogeneous AP, at the stage of 
smooth/dense plaque (hereafter referred to as dense), and heterogeneous AP at the stage of destruction (loose plaque).

\subsection{Research Methods}

All the fat tissues were previously dryed by method of J. Decock and Hubert Vanhaecke (1999) [7]. Infrared (IR) spectrometry was performed on a Termo Nicolet 5700 spectrometer (USA) using OMNIC software. Atomic adsorptive analysis was done on an AAS-1 spectrometer (Germany). For the study of organic compounds by IR, wave lengths of 2-50 micrometers were used, corresponding to $v=5000-200 \mathrm{~cm}-1$. For positive equipment controls, potassium bromide $(\mathrm{KBr})$ and sodium nitrate $\left(\mathrm{NaNO}_{3}\right)$, with enthalpy of melting peaks at $753.3^{\circ} \mathrm{C}$ (per $73.3 \mathrm{~min}$ ) and $311.1^{\circ} \mathrm{C}$ (per $58.4 \mathrm{~min}$ ), respectively, were used.

The number and position of peaks in the IR absorption spectrum have been previously discussed with respect to the nature of the substance measured (qualitative analysis) and the intensity of the absorption edge (quantitative analysis) [8].

Chemical groups and compounds were studied by IR: methyl groups $\left(-\mathrm{CH}_{3}\right)$, hydrocarbon chains $\left(\mathrm{R}-(\mathrm{CH})_{2}-\mathrm{R}\right)$, hydroxyl groups $(-\mathrm{OH})$, unsaturated hydrocarbon groups $(-\mathrm{C}=\mathrm{C}-)$ in open circuit, acetyl groups $(-\mathrm{C} \equiv \mathrm{C}-)$, unsaturated hydrocarbon chains $(-\mathrm{C}=\mathrm{C}-)$ in benzene (aromatic) nuclei, ketones/aldehydes ( $\mathrm{R}^{\prime} \mathrm{R} "-\mathrm{C}=\mathrm{O}$ ), nitrile (cyano-) groups (R'R"-C = N-R), nitro groups (R-NO2), sulphide oxide, sulphides, sulfphonamides (R2-SO $\mathrm{S}_{2}$, phosphates $\left(-\mathrm{PO}_{4}\right)$, and -C-Cl-bonds.

Characteristic vibrations measured were those with hydrogen and deuterium atoms, as well as with groups containing double and triple bonds: $-\mathrm{OH},-\mathrm{NH},-\mathrm{SH}, \mathrm{CH}$, $\mathrm{C}=\mathrm{C}, \mathrm{C}=\mathrm{O}, \mathrm{C}=\mathrm{N}, \mathrm{C}=\mathrm{C}=\mathrm{O}, \mathrm{N}=\mathrm{O}, \mathrm{S}=\mathrm{O}, \mathrm{P}=\mathrm{O}$, etc. Sets of frequencies of characteristic oscillations were tabulated in a correlation table.

Elemental chemical analysis of various lipids was carried out by passing oxygen in a fast stream (burning) using a Derivatography Simultaneous Termal Analysis409 with PC Luxx computer processing (NETZSCH, Germany) with a category temperature range of $120^{\circ} \mathrm{C}$ to $1650^{\circ} \mathrm{C}$. The temperature in the muffle furnace gradually rose to $120^{\circ} \mathrm{C}$, and at $600^{\circ} \mathrm{C}$ only ash remained in the crucible. For determination of sodium and calcium ions, atomic adsorptive spectrometry was used. Carbon (C), oxygen $(\mathrm{O})$, hydrogen $(\mathrm{H})$, hydroxyl groups $(-\mathrm{OH})$, carboxyl groups $\left(-\mathrm{CO}_{2}\right)$, calcium $(\mathrm{Ca})$, and sodium $(\mathrm{Na})$ contents were determined.

For statistical analysis, Student's t-test (without Bonferroni correction because $n=252$ ) and odds ratios (OR) with confidence interval (CI) were used. The study data are presented in tables as mean \pm standard error of the mean $(\mathrm{M} \pm \mathrm{SEM})$, and $\mathrm{P}$ values of $<0.05$ were considered significant. Statistical analysis was performed using SPSS for Windows version 17.0 (SPSS: An IBM Company, Armunk, NY) and Microsoft Excel-2010.

Table 1. Content of chemical functional groups and compounds determined by IR spectrometry in various lipids sample from different anatomical sites (expressed as percent values) $(n=252)$

\begin{tabular}{|c|c|c|c|c|c|c|c|c|}
\hline $\begin{array}{l}\text { Chemical Functional } \\
\text { Groups and } \\
\text { Compounds }\end{array}$ & $\begin{array}{l}\text { IR } \\
\text { length } \\
\text { (cm-1) }\end{array}$ & AP (dense) & AP (loose) & $\begin{array}{l}\text { VF } \\
\text { (omentum) }\end{array}$ & $\begin{array}{l}\text { VF } \\
\text { (pararenal } \\
\text { fat) }\end{array}$ & $\begin{array}{l}\text { SF } \\
\text { (buttocks) }\end{array}$ & $\begin{array}{l}\text { SF } \\
\text { (umbilical } \\
\text { region) }\end{array}$ & $\begin{array}{l}\text { SF } \\
\text { (shoulder) }\end{array}$ \\
\hline Methyl, $-\mathrm{CH}_{3}$ & 2922.1 & $1.32 \pm 0.18$ & $0.17 \pm 0.03$ & $0.51 \pm 0.03$ & $0.51 \pm 0.02$ & $0.78 \pm 0.04$ & $1.15 \pm 0.08$ & $0.45 \pm 0.04$ \\
\hline $\begin{array}{ll}\text { Hydrocarbon, } & \text { R- } \\
\left(\mathrm{CH}_{2}\right)-\mathrm{R} & \\
\end{array}$ & 2852.0 & $\begin{array}{ll}0.81 & \pm \\
0.009 & \\
\end{array}$ & $0.11 \pm 0.007$ & $0.34 \pm 0.06$ & $0.35 \pm 0.05$ & $0.55 \pm 0.03$ & $0.71 \pm 0.03$ & $0.32 \pm 0.01$ \\
\hline Hydroxyl, -OH & 3296.0 & $1.05 \pm 0.09$ & $0.24 \pm 0.01$ & $0.36 \pm 0.02$ & $0.43 \pm 0.04$ & $0.06 \pm 0.006$ & $0.28 \pm 0.03$ & $0.06 \pm 0.002$ \\
\hline $\begin{array}{l}\mathrm{C}=\mathrm{C} \text { - in open } \\
\text { circuit }\end{array}$ & 3008.1 & $\begin{array}{ll}0.01 & \pm \\
0.001 & \\
\end{array}$ & $0.07 \pm 0.006$ & $0.13 \pm 0.01$ & $0.13 \pm 0.006$ & $0.09 \pm 0.005$ & $0.21 \pm 0.028$ & $0.06 \pm 0.003$ \\
\hline Acetyl, -C $\equiv \mathrm{C}-$ & 2128.0 & $\begin{array}{ll}0.04 & \pm \\
0.007 & \\
\end{array}$ & $0.03 \pm 0.005$ & $\begin{array}{ll}0.04 & \pm \\
0.006 & \\
\end{array}$ & $0.05 \pm 0.005$ & $0.01 \pm 0.002$ & $0.01 \pm 0.001$ & $0.01 \pm 0.001$ \\
\hline $\begin{array}{l}-\mathrm{C}=\mathrm{C} \text { - in benzene } \\
\text { (aromatic) nucleus }\end{array}$ & 1465.0 & $0.46 \pm 0.05$ & $0.09 \pm 0.005$ & $0.25 \pm 0.02$ & $0.25 \pm 0.04$ & $0.31 \pm 0.04$ & $0.52 \pm 0.05$ & $0.18 \pm 0.05$ \\
\hline 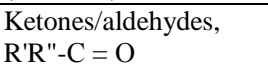 & 1743.2 & $1.82 \pm 0.22$ & $0.11 \pm 0.025$ & $0.61 \pm 0.08$ & $0.78 \pm 0.03$ & $0.96 \pm 0.04$ & $1.42 \pm 0.07$ & $0.55 \pm 0.04$ \\
\hline $\begin{array}{l}\text { Nitrile (cyano-), R'R"- } \\
\mathrm{C}=\mathrm{N}-\mathrm{R}\end{array}$ & $\begin{array}{l}1645, \\
1652\end{array}$ & $0.34 \pm 0.04$ & $0.20 \pm 0.04$ & $0.26 \pm 0.04$ & $0.31 \pm 0.05$ & $0.08 \pm 0.003$ & $0.24 \pm 0.04$ & $0.08 \pm 0.003$ \\
\hline Nitro, R-NO & 1541.0 & $0.27 \pm 0.03$ & $0.13 \pm 0.04$ & $0.14 \pm 0.05$ & $0.16 \pm 0.06$ & $0.04 \pm 0.003$ & $0.13 \pm 0.04$ & $0.05 \pm 0.005$ \\
\hline $\begin{array}{l}\text { Sulfide } \quad \text { oxide, } \\
\mathrm{R}_{2}\left(\mathrm{SO}_{2}\right)\end{array}$ & $\begin{array}{l}1416, \\
1398, \\
1378, \\
1240\end{array}$ & $0.56 \pm 0.03$ & $0.08 \pm 0.004$ & $0.18 \pm 0.04$ & $0.19 \pm 0.03$ & $0.19 \pm 0.03$ & $0.32 \pm 0.03$ & $0.11 \pm 0.04$ \\
\hline $\begin{array}{lr}\text { Sulfide } & \text { oxide, } \\
\text { sulfides, sulfonamides }\end{array}$ & $\begin{array}{l}1113 \\
1089\end{array}$ & $0.92 \pm 0.07$ & $0.09 \pm 0.008$ & $0.28 \pm 0.08$ & $0.28 \pm 0.09$ & $0.35 \pm 0.08$ & $0.57 \pm 0.07$ & $0.19 \pm 0.09$ \\
\hline Phosphates, - $\mathrm{PO}_{4}$ & 1161 & $1.12 \pm 0.12$ & $0.09 \pm 0.01$ & $0.44 \pm 0.04$ & $0.41 \pm 0.02$ & $0.62 \pm 0.05$ & $0.95 \pm 0.09$ & $0.34 \pm 0.02$ \\
\hline \multirow{3}{*}{-C-Cl-bond } & 753 & $0.74 \pm 0.09$ & $0.19 \pm 0.07$ & $0.55 \pm 0.08$ & $0.71 \pm 0.09$ & $0.44 \pm 0.07$ & $0.65 \pm 0.07$ & $0.24 \pm 0.04$ \\
\hline & 723 & $0.86 \pm 0.09$ & $0.22 \pm 0.07$ & $0.66 \pm 0.09$ & $0.82 \pm 0.11$ & $0.49 \pm 0.07$ & $0.78 \pm 0.07$ & $0.31 \pm 0.05$ \\
\hline & 697 & $0.91 \pm 0.09$ & $0.24 \pm 0.05$ & $0.62 \pm 0.08$ & $0.81 \pm 0.14$ & $0.39 \pm 0.05$ & $0.73 \pm 0.05$ & $0.25 \pm 0.05$ \\
\hline
\end{tabular}

Abbreviations: IR, Infrared; AP, atherosclerotic plaque; VF, visceral fat; SF, subcutaneous fat

\section{Results}

Qualitative and quantitative chemical composition of various lipids according to IR spectrometry are presented in Table 1 and correlated with the anatomical site of origin of the samples. As shown in Table 1, the content of 
chemical radicals and compounds in lipids differed significantly according to anatomical origin. These data are also presented in a visual form in Figure 1 shows that the highest levels of saturated fatty acids and almost all chemical groups and compounds analysed are found in dense AP. In those samples, relatively more compounds -
$\mathrm{CH}_{3},-\mathrm{PO}_{4}$, - $\mathrm{OH}$, saturated -C-C group, ketone, phenol, $\mathrm{N}$-, $\mathrm{S}-$, and $\mathrm{Cl}$-containing metabolic products $(\mathrm{P}<0.05)$ were identified. This may indicate the presence in dense AP of long-chain saturated fatty acids and relatively high concentrations of methyl groups.

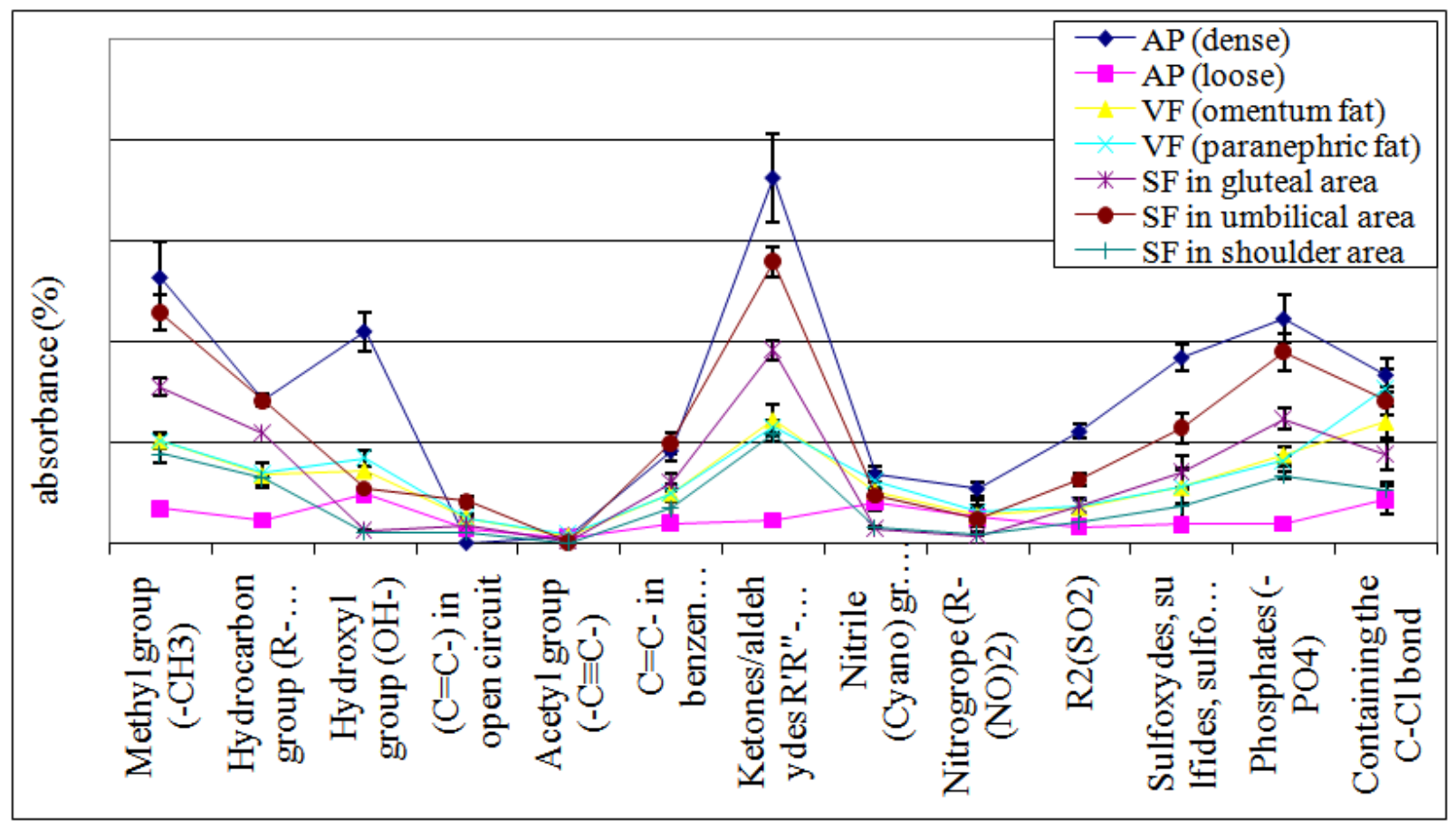

Figure 1. Graphical representation of content of chemical functional groups and compounds summarized in Table $1(\mathrm{P}<0.05, \mathrm{n}=252)$

Abbreviations: AP, atherosclerotic plaque; VF, visceral fat; SF, subcutaneous fat

The nitrogen content of the lipids in the form of urea, uric acid, creatinine, indole, skatole, cadaverine, and others may indicate the presence of proteinaceous material and (or) metabolic product [9]. The sulfur content may also indicate the presence of protein metabolic product. The content of open circuit hydrocarbon $(-\mathrm{C}=\mathrm{C}-)$ indicates the presence of unsaturated fatty acids [10].

Figure 1 shows that dense AP fundamentally is able to deposit different substances of protein metabolism, fat and protein particles or lipoproteins $(\mathrm{P}<0.05)$. This may indicate that dense AP is able to deposit different substances of protein metabolism, fats, fat and protein particles, or lipoproteins. Evidently, the type and ratio of fat and protein particles in AP are present in a dynamic state. In comparison, the content of analysed chemical groups in AP (loose) is extremely low. It is possible that this latter stage is associated with destruction of AP and calcification [11].

Chemical analysis of VF, taken from omentum and paranephric adipose tissue, shows significant differences in the content of chemical groups and compounds analysed $(P>0.05)$. IR spectroscopy data indicate the presence of high levels of ketone bodies in SF from the umbilical region of abdomen $(\mathrm{P}>0.05)$. If we assume that accumulation of fat is high in the abdomen (leading to abdominal obesity), then the data in Table 1 and Figure 1 reveal the following: -C-C- groups, $-\mathrm{CH}_{3},-\mathrm{OH},-\mathrm{S},-\mathrm{PO}_{4}$, and ketone/aldehydes are found at higher levels in the subcutaneous region of abdomen than in the buttocks and shoulder. It is possible that the central part of the human body, which is relatively immobile, is a favoured position for accumulation of metabolic toxins in SF.

Table 2. Elemental analysis of various lipids in tissue samples $(n=252)$

\begin{tabular}{|l|c|c|c|c|c|c|c|}
\hline & $\mathrm{CO}_{2}(\mathrm{gr} / \mathrm{ml})$ & $\mathrm{OH}-(\mathrm{gr} / \mathrm{ml})$ & Carbon $(\%)$ & Hydrogen $(\%)$ & Oxygen $(\%)$ & $\mathrm{Ca}(\mathrm{mcg} / \mathrm{ml})$ & $\mathrm{Na}(\mathrm{mcg} / \mathrm{ml})$ \\
\hline Atheroma (dense) & $298.0 \pm 15.2$ & $124.0 \pm 8.3$ & $52.0 \pm 2.3$ & $15.1 \pm 0.3$ & $28.9 \pm 1.0$ & $16.0 \pm 2.3$ & $41.3 \pm 5.9$ \\
\hline Atheroma (loose) & $52.69 \pm 4.1$ & $89.0 \pm 5.3$ & $13.6 \pm 0.8$ & $7.99 \pm 0.4$ & $25.4 \pm 0.9$ & $47.3 \pm 6.8$ & $22.3 \pm 3.2$ \\
\hline VF (omentum fat) & $255.9 \pm 13.2$ & $41.6 \pm 4.5$ & $69.8 \pm 2.4$ & $10.4 \pm 0.9$ & $15.8 \pm 1.0$ & $1.9 \pm 0.3$ & $18.4 \pm 3.1$ \\
\hline VF (pararenal fat) & $241.9 \pm 12.9$ & $45.9 \pm 5.8$ & $66.0 \pm 1.9$ & $10.8 \pm 0.8$ & $19.2 \pm 0.9$ & $1.4 \pm 0.2$ & $13.4 \pm 2.2$ \\
\hline SF in buttock area & $243.6 \pm 11.8$ & $47.6 \pm 5.4$ & $66.5 \pm 2.5$ & $11.6 \pm 0.8$ & $17.9 \pm 0.9$ & $1.5 \pm 0.3$ & $12.7 \pm 2.1$ \\
\hline SF in umbilical area & $243.3 \pm 16.8$ & $113.1 \pm 7.6$ & $67.2 \pm 2.4$ & $11.1 \pm 0.9$ & $17.8 \pm 1.0$ & $2.3 \pm 0.4$ & $13.5 \pm 2.2$ \\
\hline SF in shoulder area & $176.3 \pm 14.5$ & $58.1 \pm 4.9$ & $49.2 \pm 2.6$ & $10.0 \pm 0.8$ & $16.8 \pm 0.9$ & $2.1 \pm 0.4$ & $11.3 \pm 1.9$ \\
\hline
\end{tabular}

Abbreviations: AP, atherosclerotic plaque; VF, visceral fat; SF, subcutaneous fat

It is also possible that body lipid-containing structures, especially dense AP, may serve as a depot for metabolic products of proteins and fats, fats themselves, protein particles, or lipoproteins.

It is possible that alimentary postprandial hyper lipidaemia actually leads to excessive deposition of lipids in the lumen of blood vessels [12]. The AP is an "accessible" site for deposition of waste products and end 
products of metabolism. The deposition of lipids in AP in blood vessel lumen may be due to an excessive amount of blood lipoproteins of low and very low density [13].

Development of the AS process can occur not only in overweight individuals, but also in those of normal body weight [14].

It is known that a minimum number of biological active substances bound to proteins are present in blood for emergency needs of the human body [15]. In this regard, lipoprotein in the blood may play a similar emergency role for supplying cells and tissues with lipids.

During evolution, it makes sense for deposition of fat in appropriate organs and tissues in order to safeguard against times of food restriction and starvation. In this regard, AP may be considered as emergency fat depots in the blood formed after caloric intake.

Elemental data analysis of studied fats in various anatomical sites sampled is presented in Table 2.

These result show that lipids significantly differ in content of chemical radicals and compounds according to site of origin $(\mathrm{P}<0.05)$. It is noted that dense AP contain the highest diversity of chemical elements and compounds. These data are also presented graphically in Figure 2, Figure 3, Figure 4, analysed according to chemical compounds $\left(\mathrm{CO}_{2}\right.$ and $\left.\mathrm{OH}\right)$, non-metal chemical elements $(\mathrm{C}, \mathrm{H}, \mathrm{O})$, and metal elements $(\mathrm{Ca}, \mathrm{Na})$.

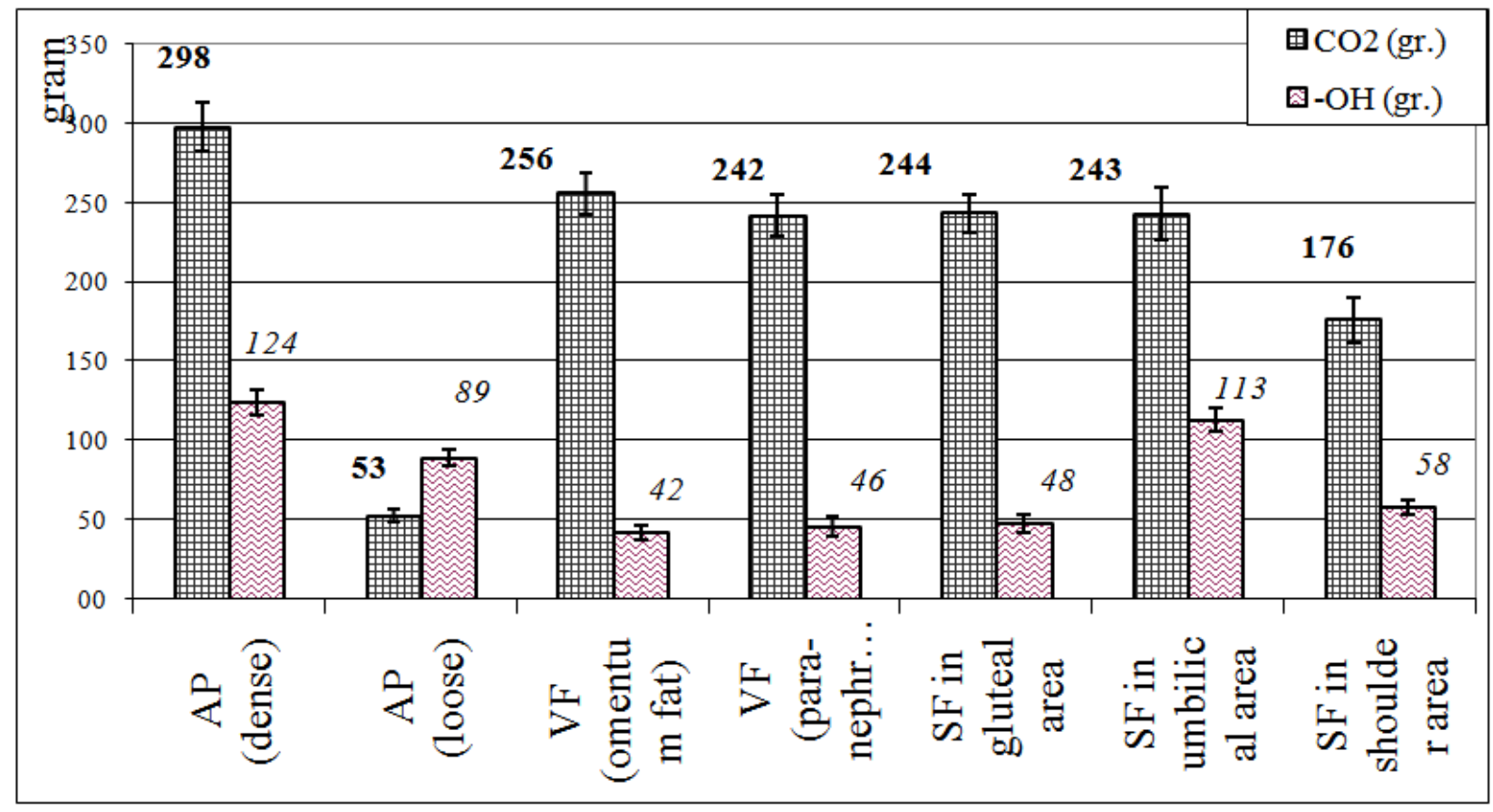

Figure 2. Content of carboxyl and hydroxyl groups in fats from different anatomic sites according to elemental analysis $(\mathrm{P}<0.05$; $\mathrm{n}=252)$ Abbreviations: AP, atherosclerotic plaque; VF, visceral fat; SF, subcutaneous fat

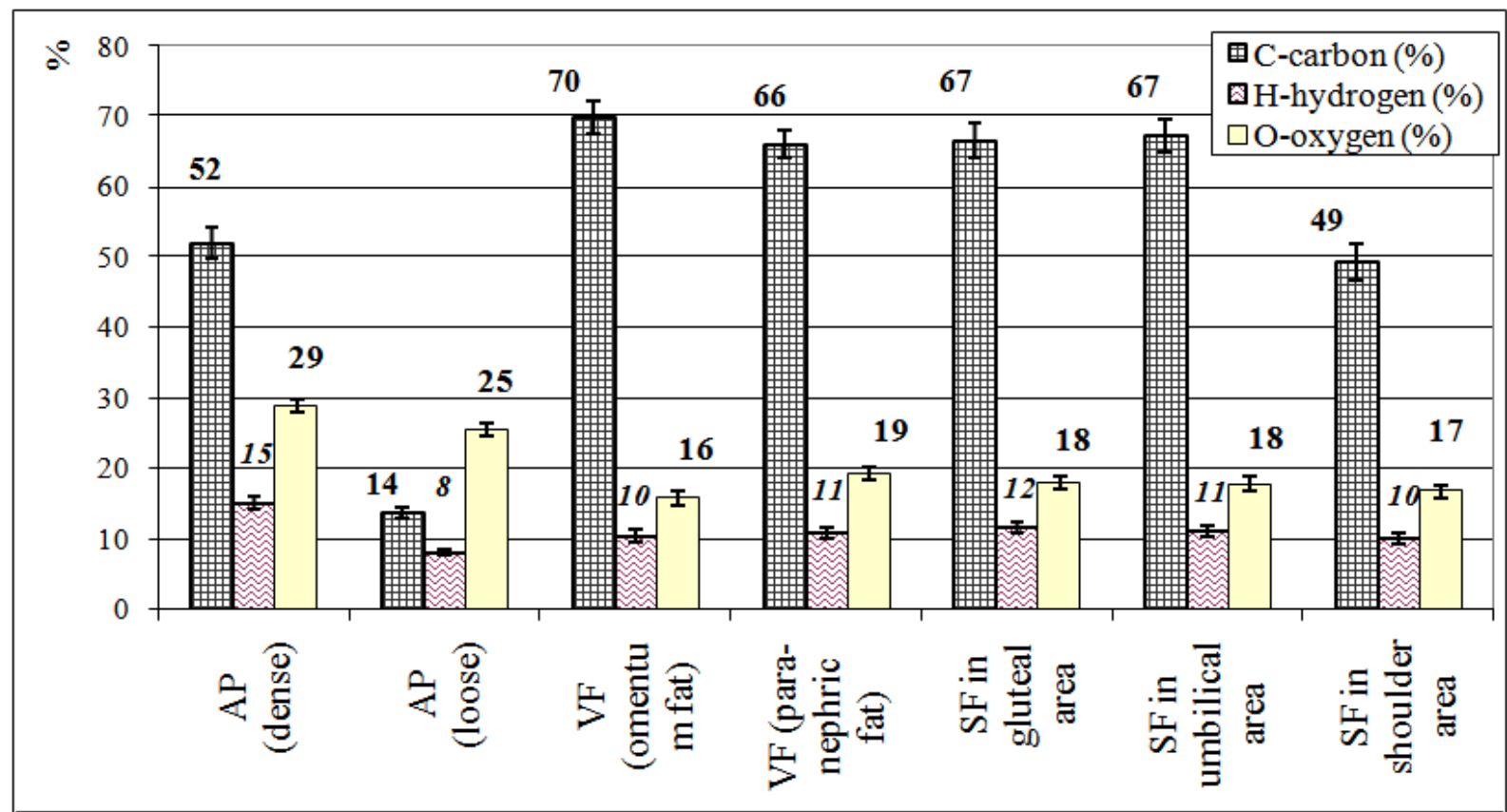

Figure 3. Percentage content of carbon $(\mathrm{C})$, oxygen $(\mathrm{O})$ and hydrogen $(\mathrm{H})$ in fats from different anatomical sites, according to elemental analysis $(\mathrm{P}<$ $0.05 ; n=252)$ 
Figure 2 shows that the content of $\mathrm{CO}_{2}$ and $-\mathrm{OH}$ groups is significantly higher in dense AP than in other lipid sources sampled $(\mathrm{P}<0.05)$. This parallels data presented in Figure 1, in which dense AP was also found to contain relatively highest amounts of long-chain saturated fatty acids and oxidised lipids.

The process of methylation and (or) hydroxylation of lipids in the human body is related to detoxification [16].

Figure 3 shows that analysis of the percentage of $\mathrm{H}$ and $\mathrm{O}$ is highest in dense AP. It is known that calorific capacity of hydrocarbons is proportional to H content [17].

The relatively high $\mathrm{O}$ content in loose AP may indicate the presence of large amounts of oxidised metabolic products. It is considered that the oxidation process is aimed to decrease toxic properties of metabolic products, and this process of oxidation frequently accompanies inflammation [18]. For example, increase of saturated fatty acids in blood serum reduce anti-inflammatory activity of blood. Inflammation is enhanced during the destabilization of AP [19]. In recent studies, surface thermometry of AP has showed direct correlation between unstable plaques and level of inflammation markers [20].

In $\mathrm{SF}$, the content of -OH groups is significantly higher when tissue sampling from the abdominal area (Figure 2). High level of ketones are also found in SF from this area.

As shown in Figure 4, the content of $\mathrm{Ca}$ is relatively higher in loose than dense AP, and the reverse is found for Na.

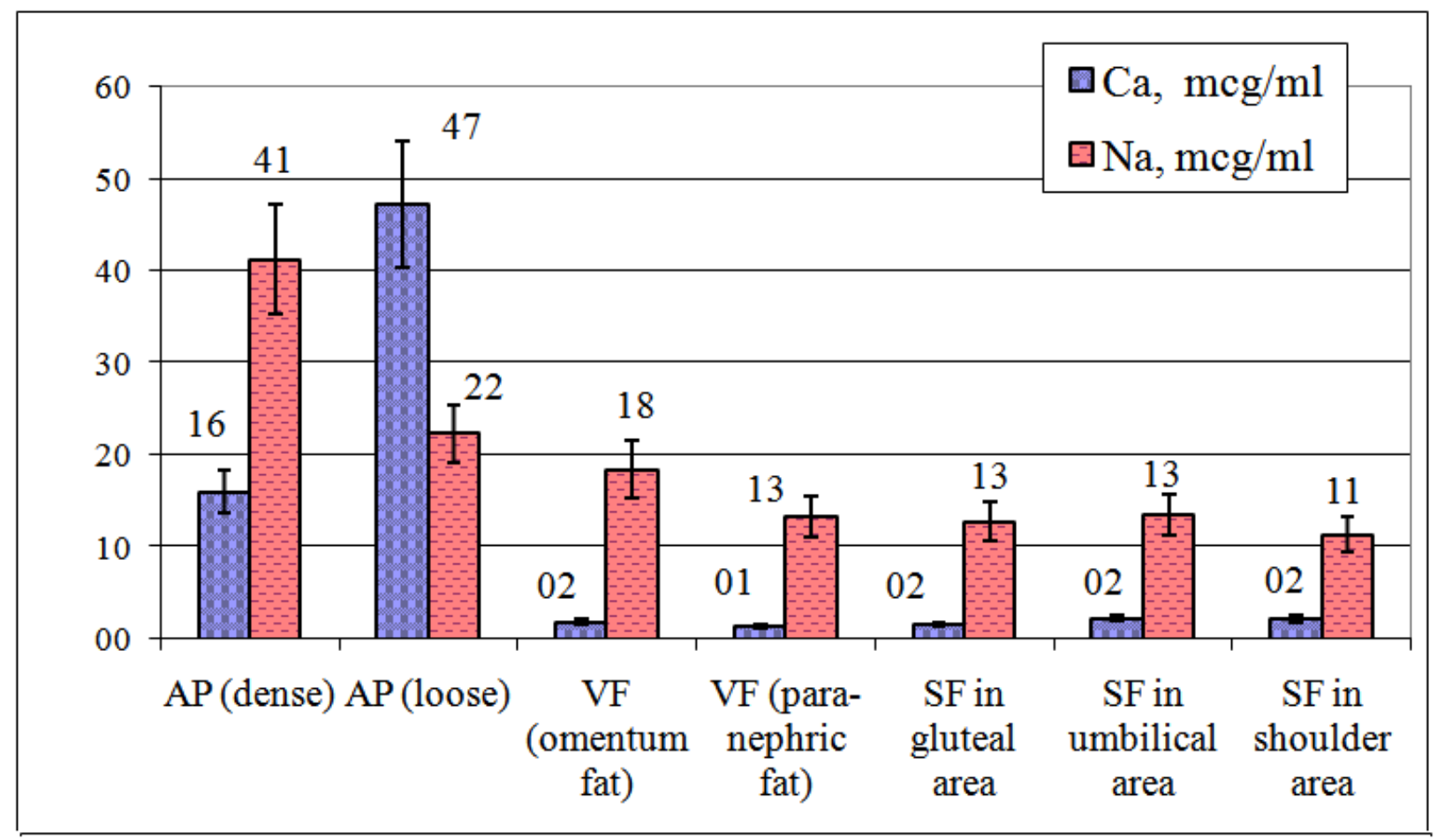

Figure 4. Calcium $(\mathrm{Ca})$ and sodium $(\mathrm{Na})$ composition of various body fats $(\mathrm{P}<0.05 ; \mathrm{n}=252)$

Abbreviations: AP, atherosclerotic plaque; VF, visceral fat; SF, subcutaneous fat

The Ca content in AP is comparatively higher, especially in loose AP. Probably, AP can deposit salt [21]. Na-ions play role in detoxification and transport in the body [22].

Elemental analysis of various lipids showed, that lipids from different locations in the human body differ by chemical composition. Dense AP contain the largest number of $\mathrm{C}, \mathrm{H}$, and $\mathrm{O}$, metals, such as $\mathrm{Na}$ and $\mathrm{Ca}$, and chemical compounds containing hydroxide and carboxide groups. This could be due to the deposition property of lipids at chronic metabolic intoxication [23].

\section{Discussion}

The process of AP formation may stretch over years due to the capacity of the body to store lipid, with transformation of body fat (24). If AP has higher energy intensity relatively to free lipids, then process of fat deposition at presence of permanent hyperlipidaemia can reflect a new method of energy resources saving.

Glycogen resources are necessary for emergency needs of the human organism. Lipogenesis occurs during periods of further increase of glucose flux. Both are resources for the long-term needs of an organism [25]. The study showed that the body lipids are heterogeneous in content, dependant on their anatomical location. Lipids in dense AP have a relatively higher content of saturated hydrocarbon chains.

AP may be a sui generis source available lipids in the blood stream. With increasing low density lipoproteins levels in blood, increased migration of leukocytes to vascular walls occurs mediated by the chemokin MCP-1 (chemotactic protein produced by monocytes) [26].

Increase of atherogenecity of lipoprotein is associated with mechanism of size increase and induration of chemical bonds of lipids [27].

Our study showed fat has ability to accumulate organic waste material, depending on anatomic site. Recent studies confirm persistent organic waste remaining in adipocytes exacerbates obesity [28,29].

The results of the investigation would be useful for improving a curative methods of atherosclerosis.

\section{Conclusion}


Fats in the body are heterogeneous in content and differ by properties. Dense AP contains relatively more saturated and branched hydrocarbon chains, and they have the largest quantities of organic and inorganic elements and compounds in their structure. Human body lipids, especially dense AP, serve as a depot for various organic substances. Possible, lipids including AP can have important pathophysiological meaning in adsorption of metabolic product sat chronic metabolic intoxication.

\section{Abbreviations}

\author{
atherosclerotic plaque (AP) \\ atherosclerosis (AS) \\ visceral fat (VF) \\ subcutaneous fat (SF) \\ Infrared (IR) \\ carbon $(\mathrm{C})$ \\ oxygen $(\mathrm{O})$ \\ hydrogen $(\mathrm{H})$ \\ hydroxyl groups $(-\mathrm{OH})$ \\ carboxyl groups $\left(-\mathrm{CO}_{2}\right)$ \\ calcium $(\mathrm{Ca})$ \\ sodium $(\mathrm{Na})$ \\ odds ratios (OR) \\ confidence interval (CI) \\ mean \pm standard error of the mean $(\mathrm{M} \pm \mathrm{SEM})$
}

\section{Acknowledgements}

We thank the grant from "Fund of the First President of the Republic of Kazakhstan”. We are grateful to scientific staff of "Institute of Chemical Sciences named A.B. Bekturov”, PhD, DSc, Espenbetov A.A., PhD, DSc, Kurmankulov N.B., and PhD, Daurenbekov K.N. We are also grateful to staff of the Almaty Center of Forensic Medicine, director, Erezhepov N.M., experts Ismailov N. and Abdraimov M. Special thank Elmira Nurakhanova for language and logistic support and for technical assistance.

\section{Competing Interests}

Conflicts of interest were not declared by any author.

\section{Endnotes}

Study limitation. Several limitations of the study deserve comment. First, the design of the present study was experimental-based, which is susceptible to selection bias. Second, the sample size was moderate, limiting its ability to detect significant results. Third, the chemical and physical investigations indicated only some of organic substances. Fourth, the heterogeneous content of organic substances in the human fats was not analyzed in the present study. Finally, it is important to mention that our study was performed on Kazakhstan citizens, and our findings may not be relevant to people of other countries.

Trial national registration: State registration \# 0109RK000079, code O.0475 at the National Center for Scientific and Technical Information, the Republic of Kazakhstan.
Trial International registration ClinicalTrials. gov NCT01700075.

Funding: Foundation Grant "Fund of the First President of the Republic of Kazakhstan” for 2009-2010, Grant \# 69-09 from 23.06.2009, and Order \# 28 from 06.05.2009.

\section{Statement of Author Contributions and Acknowledgements}

Kuat P. Oshakbayev: design and performance, scientific executor, collecting of the practical material, bibliography review, scientific analysis, statistical advancing, writing of the paper.

Kenneth Alibek: design and performance, scientific executor, paper review, writing of the manuscript.

Igor O. Ponomarev: design and performance, scientific executor, collecting of the practical material, scientific analysis, writing of the paper.

NurlybekUderbayev: design and performance, scientific executor, collecting of the autopsy material.

Bibazhar A. Dukenbayeva: gathering autopsy material, preparation e-version statistical data in Excel, bibliography search and review, scientific analysis, writing the paper.

Meruyert A. Gazaliyeva: preparation e-version statistical data in Excel, gathering autopsymaterial, bibliography search and review, scientific analysis, paper print.

Pernekul Oshakbayev: design, bibliography search and review, scientific analysis and writing the paper.

Sholpan Kaliyeva: review the paper, collect of the clinical material, patient's diagnosis, scientific analysis.

\section{References}

[1] Dahlback B, Ahnstrom J, Christoffersen Ch. Apolipoprotein M: structure and function. Future Lipidology 2008; 3 (5): 495-503.

[2] Rerkasem K, Gallagher PJ, Grimble RF. Managing hypercholesterolemia and its correlation with carotid plaque morphology in patients undergoing carotid endarterectomy. Vascular health and risk management 2008; 4 (6): 1259-1264.

[3] Kubo T, Maehara A, Mintz GS.The Dynamic Nature of Coronary Artery Lesion Morphology Assessed by Serial Virtual Histology Intravascular Ultrasound Tissue Characterization. Journal of the American College of Cardiology 2010; 55 (15): 1590-1597.

[4] Olgac U, Knight J, Poulikakos D. Computed high concentrations of low-density lipoprotein correlate with plaque locations in human coronary arteries. Journal of Biomechanics 2011; 44 (13): 2466-2471.

[5] FukuchiM, Watanabe J, Kumagai K. Normal and oxidized low density lipoproteins accumulate deep in physiologically thickened intima of human coronary arteries. Laboratory Investigation, 2002; 82 (10): 1437-1447.

[6] Kim MJ, Pelloux V, Guyot E. Inflammatory Pathway Genes Belong to Major Targets of Persistent Organic Pollutants in Adipose Cells. Environmental Health Perspectives 2012; 120 (4): 508-514.

[7] Decock J, Vanhaecke H. Method and apparatus for drying fat or oil containing substances. Patent EP 0926229 A1; priority date Dec 24, 1997; publication date Jun 30, 1999.

[8] Prieto N, Dugan ME, López-Campos O, McAllister TA, Aalhus JL, Uttaro B. Near infrared reflectance spectroscopy predicts the content of polyunsaturated fatty acids and biohydrogenation products in the subcutaneous fat of beef cows fed flaxseed. Meat Science 2012; 90 (1): 43-51.

[9] Riemenschneider A, Nikiforova V, Hoefgen R. Impact of elevated $\mathrm{H} 2 \mathrm{~S}$ on metabolite levels, activity of enzymes and expression of 
genes involved in cysteine metabolism. Plant Physiology And Biochemistry, 2005; 43 (5): 473-483.

[10] Kiefer J, Noack K, Bartelmess J. Vibrational structure of polyunsaturated fatty acids eicosapentaenoic acid and arachidonic acid studied by infrared spectroscopy. Journal of Molecular Structure 2009; 965 (1-3): 121-124.

[11] Fabiano S, Mancino S, Stefanini M. High-resolution multicontrast-weighted MR imaging from human carotid endarterectomy specimens to assess carotidplaque components. European Radiology 2008; 18 (12): 2912-2921.

[12] Chen XH, Lu ZhL, Guo FJ. The relationship between hyperlipidemia and lower limb arterial disease in elderly diabetes patients. Chinese journal of internal medicine 2008; 47 (7): 556559.

[13] Lind PM, van Bavel B, Salihovic S. Circulating levels of persistent organic pollutants and carotid atherosclerosis in the elderly. Environmental Health Perspectives 2012; 120 (1): 38-43.

[14] Naganuma R, Sakurai M, Miura K. Relation of long-term body weight change to change in lipoprotein particle size in Japanese men and women: The INTERMAP Toyama Study. Atherosclerosis 2009; 206 (1): 282-286.

[15] Hermansson A, Ketelhuth DF, Strodthoff D. Inhibition of T cell response to native low-density lipoprotein reduces atherosclerosis. J Exp Med 2010; 10, 207 (5): 1081-1093.

[16] Hovander L, Malmberg T, Athanasiadou M. Identification ofhydroxylated PCB metabolites and other phenolic halogenated pollutants in human blood plasma. Archives of Environmental Contamination and Toxicology 2002; 42 (1): 105-117.

[17] Valliyappan T, Ferdous D, Bakhshi NN. Production of hydrogen and syngas via steam gasification of glycerol in a fixed-bed reactor. Topics in Catalysis 2008; 49 (1-2): 59-67.

[18] Ault KA, Cannon CP, Mitchell J. Platelet activation in patients after an acute coronary syndrome: results from the TIMI-2 trial. Thrombolysis in myocardial infarction. J. Amer. Coll. Cardiology 1999; 33: 634-639.

[19] Patel S, Puranik R, Nakhla S. Acute hypertriglyceridaemia in humans increases the triglyceride content and decreases the antiinflammatory capacity of high density lipoproteins. Atherosclerosis 2009; 204 (2): 424-428.
[20] Toutouzas K, Synetos A, Stefanadi E. Correlation between morphologic characteristics and local temperature differences in culprit lesions of patients with symptomatic coronary artery disease. Journal of the American College of Cardiology 2007; 49 (23): 2264-2271.

[21] Siener R, Ebert D, Nicolay C, Nesse A. A case-control study of dietary risk factors for hyperoxaluria in calcium oxalate stone formers. European Urology 2003; 2, 80: 309.

[22] Oshakbayev KP, Nuralin RSh, Bolshakova SV, Seydalieva AP, Kozhanov KS. The functional role of electrolytes in endogenous intoxication. Therapeutic Bulletin 2005; 4 (8): 40-43.

[23] La Merrill M, Emond C, Kim MJ. Toxicological Function of Adipose Tissue: Focus on Persistent Organic Pollutants. Environ Health Perspect 2013; 121 (2): 162-169.

[24] Zhang Yi, Sonnenberg, GE, Baye TM. Obesity-related dyslipidemia associated with FAAH, independent of insulin response in multigenerational families of Northern European descent. Pharmacogenomics 2010; 10 (12): 1929-1939.

[25] Levin K, Daa Schroeder H, Alford FP, Beck-Nielsen H. Morphometric documentation of abnormal intramyocellular fat storage and reduced glycogen in obese patients with Type II diabetes. Diabetologia 2001; 44 (7): 824-833.

[26] Tang D, Yang C, Mondal S, Liu F. A negative correlation between human carotid atherosclerotic plaque progression and plaque wall stress: in vivo MRI-based 2D/3D FSI models. $J$ Biomech 2008; 41 (4): 727-736.

[27] Tertov VV, Kaplun VV, Sobenin IA, Orekhov AN. Low-density lipoprotein modification occurring in human plasma possible mechanism of in vivo lipoprotein desialylation as a primary step of atherogenic modification. Atherosclerosis 1998; 138 (1): 183195.

[28] Ruzzin J, Petersen R, Meugnier E. Persistent organic pollutant exposure leads to insulin resistance syndrome. Environmental Health Perspectives 2010; 118 (4): 465-471.

[29] Dirinck E, Jorens PG, Covaci A. Obesity and persistent organic pollutants: possible obesogenic effect of organochlorine pesticides and polychlorinated biphenyls. Obesity (Silver Spring) 2011; 19 (4): 709-714. 